\title{
Inhaled nitric oxide decreases pulmonary soluble guanylate cyclase protein levels in 1-month-old lambs
}

\author{
Stephan Thelitz, MD \\ Janine M. Bekker, BS ${ }^{b}$ \\ Boaz Ovadia, MD ${ }^{\mathrm{b}}$ \\ Regan B. Stuart, $M D^{b}$ \\ Michael J. Johengen, BS ${ }^{b}$ \\ Stephen M. Black, PhD ${ }^{\mathrm{C}}$ \\ Jeffrey R. Fineman, $M D^{b, d}$
}

From the Departments of Cardiothoracic Surgery $^{\mathrm{a}}$ and Pediatrics, ${ }^{\mathrm{b}}$ University of California, San Francisco, San Francisco, Calif, Department of Pediatrics, ${ }^{\mathrm{c}}$ Northwestern University Medical School, Chicago, Ill, and the Cardiovascular Research Institute, ${ }^{\mathrm{d}}$ University of California, San Francisco, San Francisco, Calif.

This research was supported by grants HL61284 (J.R.F.), HL07061 (S.M.B.), and HD398110 (S.M.B.) from the National Institutes of Health

Received for publication June 21, 2003; revisions requested July 17, 2003; revisions received July 22, 2003; accepted for publication July 31, 2003.

Address for reprints: Jeffrey R. Fineman, MD, Medical Center at UC San Francisco, 505 Parnassus Ave, Box 0106, San Francisco, CA 94143-0106 (E-mail: jfineman@ pedcard.ucsf.edu)

J Thorac Cardiovasc Surg 2004;127:1285-92

$0022-5223 / \$ 30.00$

Copyright $\odot 2004$ by The American Association for Thoracic Surgery

doi:10.1016/j.jtcvs.2003.07.024
Background: Inhaled nitric oxide produces potent pulmonary vasodilation by activating soluble guanylate cyclase and increasing smooth muscle cell concentrations of cyclic guanosine monophosphate. However, responses are often nonsustained, and clinically significant increases in pulmonary vascular resistance have been noted on its acute withdrawal. In vitro and in vivo data suggest that inhaled nitric oxide decreases endogenous nitric oxide synthase activity. The effects of inhaled nitric oxide on the downstream mediators of the nitric oxide/cyclic guanosine monophosphate cascade, soluble guanylate cyclase and phosphodiesterase 5, have not been investigated. We sought to determine the effects of inhaled nitric oxide on endogenous cyclic guanosine monophosphate levels, soluble guanylate cyclase, and phosphodiesterase 5 protein levels in the intact lamb.

Methods: Eleven 1-month-old lambs were mechanically ventilated. In 7 lambs, inhaled nitric oxide $(40 \mathrm{ppm})$ was administered for 24 hours and then acutely withdrawn. Intermittent lung biopsy samples were obtained for cyclic guanosine monophosphate concentrations and soluble guanylate cyclase and phosphodiesterase 5 protein levels (Western blot analysis).

Results: Initiation of nitric oxide decreased left pulmonary vascular resistance by $26.2 \%$, and withdrawal rapidly increased pulmonary vascular resistance by $77.8 \%(P<$ $.05)$. Tissue cyclic guanosine monophosphate concentrations initially increased during nitric oxide therapy but were not maintained during the 24-hour exposure. In addition, cyclic guanosine monophosphate concentrations rapidly decreased after nitric oxide withdrawal $(P<.05)$. The $\alpha$ soluble guanylate cyclase $(-45.7 \%)$ and $\beta$ soluble guanylate cyclase $(-48.4 \%)$ protein levels decreased during nitric oxide therapy $(P<$ .05 ), whereas phosphodiesterase 5 proteins levels were unchanged.

Conclusions: These data suggest a role for decreased soluble guanylate cyclase and its resulting decrease in cyclic guanosine monophosphate concentrations in the nonsustained response to nitric oxide and the rebound pulmonary hypertension noted on its acute withdrawal. Phosphodiesterase 5 inhibitors may be a useful adjunct therapy during inhaled nitric oxide to preserve cyclic guanosine monophosphate levels and thereby preserve nitric oxide responsiveness and prevent rebound pulmonary hypertension.

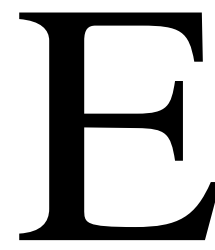

xogenously administered inhaled nitric oxide (NO) is currently used as an adjuvant therapy for a number of pulmonary hypertensive disorders. In both animal and human studies, inhaled NO (5 to 80 $\mathrm{ppm}$ ) induces rapid and selective pulmonary vasodilation. ${ }^{1-4}$ When administered into the airways in its gaseous form, NO diffuses into pulmonary vascular smooth muscle cells and activates soluble guanylate cyclase (sGC), a heterodimer with $\alpha_{1}$ and $\beta_{1}$ subunits that catalyzes the 
production of cyclic guanosine monophosphate (cGMP) from guanosine-5'-triphosphate. Cyclic GMP induces vascular smooth muscle relaxation through activation of a cGMP-dependent protein kinase, although the exact mechanism remains unclear. ${ }^{5,6}$ Cyclic nucleotide phosphodiesterases (PDEs) regulate intracellular levels of cGMP by catalyzing cGMP to GMP. ${ }^{7}$ PDE 5 is the predominant cGMP-metabolizing PDE of pulmonary tissues. ${ }^{8}$ Several clinical trials have demonstrated that inhaled NO improves oxygenation and decreases the need for extracorporeal life support in neonates with persistent pulmonary hypertension. ${ }^{2,3}$ In addition, nonrandomized studies demonstrate that inhaled NO selectively decreases pulmonary arterial pressure and pulmonary vascular resistance in patients with perioperative pulmonary hypertension and decreases pulmonary vascular resistance and improves oxygenation in patients with acute lung injury. ${ }^{1,4}$

Although these data are encouraging, nonsustained responsiveness is common, and concerns regarding the safety of inhaled NO therapy remain. For example, in acute lung injury, inhaled NO improves oxygenation on initiation, but this effect is not sustained. ${ }^{9,10}$ In addition, several studies have noted a potentially life-threatening increase in pulmonary vascular resistance on acute withdrawal of inhaled NO. ${ }^{11,12}$ This rebound pulmonary hypertension is manifested by an increase in pulmonary vascular resistance, compromised cardiac output, severe hypoxemia, or a combination of these. ${ }^{11,12}$ Increasing data demonstrate that exogenous NO exposure inhibits endogenous endothelial NO synthase (NOS) activity, suggesting that transient decreases in endogenous NOS activity during inhaled NO therapy may be a potential mechanism for rebound pulmonary hypertension. ${ }^{13-15}$ Limited in vitro data suggest that exogenous NO may directly alter sGC gene expression. ${ }^{16,17}$ However, the potential effects of inhaled NO on pulmonary sGC and PDE 5 signaling in vivo are unknown.

The purpose of this study was to investigate the effects of inhaled NO endogenous sGC and PDE 5 protein levels in the intact lamb. To this end, inhaled NO (40 ppm) was administered to 7 intact 1-month-old lambs for 24 hours and then acutely withdrawn. Sequential blood was taken for plasma cGMP determinations, and sequential peripheral lung biopsy samples were taken for tissue cGMP determinations and protein level determinations of sGC and PDE 5 by Western blot analysis. Four additional lambs underwent an identical protocol without inhaled NO therapy.

\section{Methods \\ Surgical Preparation}

Eleven lambs (30.1 \pm 4.3 days old) were fasted for 24 hours, with free access to water. The lambs were then anesthetized with ketamine hydrochloride ( $15 \mathrm{mg} / \mathrm{kg}$ intramuscularly). With lambs under additional local anesthesia with $1 \%$ lidocaine hydrochloride, polyurethane catheters were placed in an artery and vein of a hind leg. These catheters were advanced to the descending aorta and the inferior vena cava, respectively. The lambs were then anesthetized with ketamine hydrochloride (approximately $0.3 \mathrm{mg} \cdot \mathrm{kg}^{-1}$. $\left.\min ^{-1}\right)$, diazepam $\left(0.002 \mathrm{mg} \cdot \mathrm{kg}^{-1} \cdot \min ^{-1}\right)$, and fentanyl citrate $\left(1.0 \mu \mathrm{g} \cdot \mathrm{kg}^{-1} \cdot \mathrm{h}^{-1}\right)$, intubated with a 7.0-mm-outer-diameter cuffed endotracheal tube, and mechanically ventilated with a Healthdyne pediatric time-cycled, pressure-limited ventilator. Pancuronium bromide $(0.1 \mathrm{mg} / \mathrm{kg}$ per dose $)$ was given intermittently for muscle relaxation. By using strict aseptic technique, a midsternotomy incision was then performed, and the pericardium was incised. By using a purse-string suture technique, polyurethane catheters were placed directly into the right and left atrium and the main pulmonary artery. An ultrasonic flow probe (Transonics Systems, Ithaca, NY) was placed around the left pulmonary artery to measure pulmonary blood flow. The midsternotomy incision was then temporarily closed with towel clamps. An intravenous infusion of Ringer's lactate and $5 \%$ dextrose $(75 \mathrm{~mL} / \mathrm{h})$ was begun and continued throughout the study period. Cefazolin (500 mg IV) and gentamicin (3 $\mathrm{mg} / \mathrm{kg} \mathrm{IV})$ were administered before the first surgical incision and every 8 hours thereafter. The lambs were maintained normothermic $\left(39^{\circ} \mathrm{C}\right)$ with a heating blanket.

\section{Experimental Protocol}

After a 30-minute recovery, baseline measurements of the hemodynamic variables (pulmonary and systemic arterial pressure, heart rate, left pulmonary blood flow, and left and right atrial pressures), systemic arterial blood gases, and $\mathrm{pH}$ were measured (before $\mathrm{NO}$ ). Blood was obtained for plasma cGMP determinations, and peripheral lung wedge biopsy samples were obtained for tissue cGMP determinations and sGC and PDE 5 protein determinations. A side-biting vascular clamp was used to isolate peripheral lung tissue from a randomly selected lobe, and the incision was cauterized. Approximately $300 \mathrm{mg}$ of peripheral lung was obtained for each biopsy sample.

In 7 of the lambs, inhaled NO (40 ppm) was then delivered in nitrogen into the inspiratory limb of the ventilator (Inovent; Ohmeda Inc, Liberty, NJ) and continued for 24 hours. The inspired concentrations of NO and nitrogen dioxide were continuously quantified by electrochemical methodology (Inovent). The hemodynamic variables were monitored continuously. Systemic arterial blood gases were determined intermittently, and ventilation was adjusted to achieve a $\mathrm{PaCO}_{2}$ between 32 and $45 \mathrm{~mm} \mathrm{Hg}$ and $\mathrm{PaO}_{2}$ greater than $50 \mathrm{~mm} \mathrm{Hg}$. Sodium bicarbonate was administered intermittently to maintain a $\mathrm{pH}$ greater than 7.30. Normal saline was administered intermittently to maintain stable atrial pressures throughout the study period. Peripheral lung wedge biopsies were performed after 2, 6, and 24 hours of therapy. The inhaled NO was then stopped, and the hemodynamic variables were monitored for 2 additional hours. To ensure that the potential changes demonstrated resulted from inhaled NO and not from mechanical ventilation alone, 4 lambs were mechanically ventilated for 24 hours, as described previously, without inhaled NO therapy.

At the end of the protocol, all lambs were killed with a lethal injection of sodium pentobarbital followed by bilateral thoracotomy as described in the National Institutes of Health Guide for the Care and Use of Laboratory Animals. All protocols and procedures were approved by the Committee on Animal Research of the University of California, San Francisco. All animals received 
humane care in compliance with the Guide for the Care and Use of Laboratory Animals.

\section{Measurements}

Pulmonary and systemic arterial and right and left atrial pressures were measured with Sorenson Neonatal Transducers (Abbott Critical Care Systems, North Chicago, Ill). Mean pressures were obtained by electrical integration. Heart rate was measured by a cardiotachometer triggered from the phasic systemic arterial pressure pulse wave. Left pulmonary blood flow was measured on an ultrasonic flow meter (Transonic Systems). All hemodynamic variables were recorded continuously on a Gould multichannel electrostatic recorder (Gould Inc, Cleveland, Ohio). Systemic arterial blood gases and $\mathrm{pH}$ were measured on a Radiometer ABL5 pH/ blood gas analyzer (Radiometer, Copenhagen, Denmark). Hemoglobin concentration and oxygen saturation were measured by a hemoximeter (model 270, Ciba-Corning, East Walpole, Mass). Pulmonary vascular resistance was calculated by using standard formulas. Body temperature was monitored continuously with a rectal temperature probe.
\end{abstract}

\section{Cyclic GMP Determinations}

Blood samples (1-2 mL) were collected in iced Vacutainer tubes (Becton Dickinson, Franklin Lakes, NJ) containing ethylenediaminetetraacetic acid $(7.5 \mathrm{mmol} / \mathrm{L})$. The samples were centrifuged ( $4000 \mathrm{~g}$ for 15 minutes), and the resulting plasma was stored in polypropylene storage tubes at $-70^{\circ} \mathrm{C}$. At the time of the assay, the plasma $(200 \mu \mathrm{L})$ was diluted $1: 1$ with $0.2 \mathrm{~mol} / \mathrm{L} \mathrm{HCL}$ and vortexed, and the acidified plasma was passed through a $0.2-\mu \mathrm{m}$ Centrex filter (Schleicher \& Schuell Inc, Keene, NH) by centrifugation ( $4000 \mathrm{~g}$ for 15 minutes). Tissue was homogenized in $6 \%$ trichloroacetic acid at $4^{\circ} \mathrm{C}$ to give a $10 \% \mathrm{wt} / \mathrm{vol}$ homogenate and centrifuged at 2000 revolutions per minute for 15 minutes at $4^{\circ} \mathrm{C}$. The supernatant was recovered and washed 4 times with 5 volumes of water-saturated diethyl ether. Aqueous extracts were then lyophilized, and the dried pellet was resuspended in assay buffer before analysis. The samples were assayed with a cGMP (iodine 125) radioimmunoassay kit (Amersham International, Amersham, UK) according to the manufacturer's instructions. Cross-reactivity for other nucleotides was less than 0.001 .

\section{Western Blot Analysis}

Western blot analysis was performed as previously described. ${ }^{18}$ Protein extracts prepared from lung biopsy samples $(100 \mu \mathrm{g})$ were separated on $10 \%$ sodium dodecyl sulfate-polyacrylamide gel and electrophoretically transferred to Hybond polyvinylidene difluoride membranes (Amersham, Arlington Heights, IL). The membranes were blocked with 5\% nonfat dry milk in Tris-buffered saline containing $0.1 \%$ Tween. After blocking, the membranes were incubated at room temperature with the appropriate dilution of the antiserum of interest (1:1000 for the $\alpha_{1}$ subunit of guanylate cyclase, 1:10,000 for the $\beta_{1}$ subunit of guanylate cyclase [antisera for the $\alpha_{1}$ subunit and the $\beta_{1}$ subunit of guanylate cyclase were a gift from Peter Yuen, PhD], or 1:2000 for PDE 5 [a gift from Dr Stefan Janssens, University Hospital Gasthuisberg, Lueven, Belgium]), washed with Tris-buffered saline containing $0.1 \%$ Tween, and then incubated with the appropriate species of anti-immunoglobulin $G$ horseradish peroxidase conjugate. After washing,

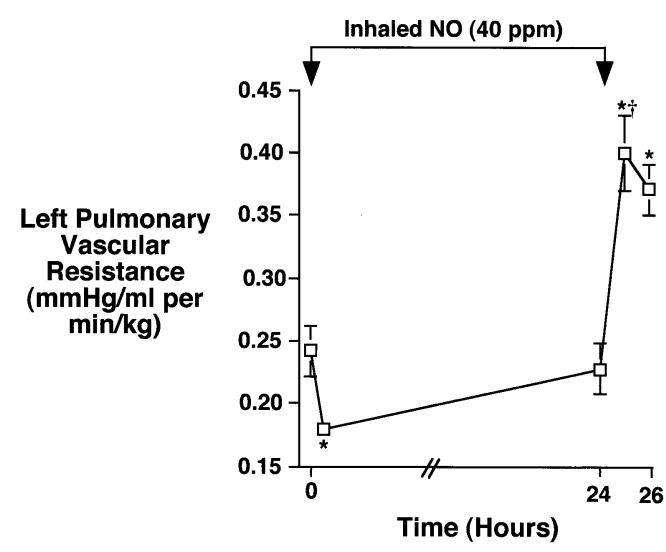

Figure 1. Changes in left pulmonary vascular resistance before, during, and after 24 hours of inhaled nitric oxide (40 ppm) therapy; $\mathrm{n}=7$ lambs. Values are mean \pm SEM. ${ }^{*} \boldsymbol{P}<.05$ versus 0 hours; $\dagger P<.05$ versus previous data point (analysis of variance).

chemiluminescence (Pierce Laboratories, Rockford, Ill) was used to detect the protein bands of interest. Quantitation of autoradiographic results was performed by scanning (Hewlett-Packard SCA Jet IICX; Hewlett-Packard Inc, Palo Alto, Calif) the bands of interest into an image-editing software program (Adobe Photoshop; Adobe Systems, Mountain View, Calif). Band intensities from Western blot analysis were analyzed densitometrically on a Macintosh computer (model 9500; Apple Computer, Inc, Cupertino, Calif) by using the public-domain NIH Image program (developed at the National Institutes of Health and available on the Internet at http://rsb.info.nih.gov/nih-image). For Western blot analysis, to ensure equal protein loading, duplicate polyacrylamide gels were run. One was stained with Coomassie blue.

\section{Statistical Analysis}

The mean $\pm \mathrm{SE}$ was calculated for the baseline hemodynamic variables, systemic arterial blood gases, $\mathrm{pH}$, and cGMP concentrations. Comparisons over time were made by analysis of variance for repeated measures. The mean $\pm \mathrm{SE}$ was calculated for the relative protein of interest from pre- and post-NO lungs. Results from pre-NO lungs were assigned the value of 1 (relative protein of interest). Comparisons were made by the paired $t$ test.

\section{Results}

Inhaled NO (40 ppm) transiently decreased mean pulmonary arterial pressure and left pulmonary vascular resistance (from to $0.242 \pm 0.04$ to $0.179 \pm 0.02 \mathrm{~mm} \mathrm{Hg} / \mathrm{mL}$ per minute per kilogram; $P<.05$; Table 1, Figure 1). Left pulmonary blood flow, mean systemic arterial pressure, heart rate, right and left atrial pressures, systemic arterial blood gases, and $\mathrm{pH}$ were all unchanged. During the 24hour treatment course, pulmonary arterial pressure returned to the pre-NO value. Systemic arterial pressure slightly decreased and systemic arterial $\mathrm{PCO}_{2}$ increased in comparison to pre-NO values (Table 1). On discontinuation of inhaled NO, there was a rapid increase in both mean pul- 
TABLE 1. The hemodynamic changes during and after 24 hours of inhaled NO

\begin{tabular}{|c|c|c|c|c|c|c|c|c|c|}
\hline \multirow[b]{2}{*}{ Variable } & \multirow[b]{2}{*}{ Before NO } & \multicolumn{4}{|c|}{ Inhaled NO (40 ppm) } & \multicolumn{4}{|c|}{ Off NO } \\
\hline & & $15 \min$ & $2 \mathrm{~h}$ & $6 \mathrm{~h}$ & $24 \mathrm{~h}$ & $10 \mathrm{~min}$ off & $30 \mathrm{~min}$ off & $60 \mathrm{~min}$ off & $120 \mathrm{~min}$ off \\
\hline $\begin{array}{c}\text { Pulmonary } \\
\text { arterial } \\
\text { pressure } \\
(\mathrm{mm} \mathrm{Hg})\end{array}$ & $13.2 \pm 1.3$ & $11.6 \pm 1.8^{*} \dagger$ & $\dagger 12.9 \pm 2.7$ & $12.0 \pm 2.0$ & $12.0 \pm 1.2$ & $16.8 \pm 0.6^{*} \dagger$ & $17.2 \pm 1.6^{*}$ & $17.1 \pm 1.6^{*}$ & $16.4 \pm 2.1^{*}$ \\
\hline $\begin{array}{l}\text { Left } \\
\text { pulmonary } \\
\text { blood flow } \\
\left(\mathrm{mL} \cdot \mathrm{kg}^{-1}\right. \\
\left.\cdot \mathrm{min}^{-1}\right)\end{array}$ & $33.3 \pm 7.3$ & $33.8 \pm 6.9$ & $33.7 \pm 6.5$ & $33.2 \pm 9.8$ & $29.1 \pm 6.1$ & $28.1 \pm 5.4^{*}$ & $31.8 \pm 4.3$ & $30.5 \pm 3.3$ & $31.1 \pm 4.4$ \\
\hline $\begin{array}{l}\text { Systemic } \\
\text { arterial } \\
\text { pressure } \\
(\mathrm{mm} \mathrm{Hg})\end{array}$ & $63.7 \pm 6.9$ & $61.7 \pm 9.5$ & $62.9 \pm 10.4$ & $60.2 \pm 10.7$ & $45.7 \pm 6.9 * \dagger$ & $48.9 \pm 15.3^{*}$ & $49.1 \pm 10.7^{*}$ & $48.3 \pm 9.2^{*}$ & $48.2 \pm 13.8^{*}$ \\
\hline $\begin{array}{l}\text { Heart rate } \\
\text { (beats/ } \\
\text { min) }\end{array}$ & $152.0 \pm 17.7$ & $142.7 \pm 14.1$ & $146.4 \pm 16.4$ & $144.0 \pm 16.5$ & $137.9 \pm 17.5$ & $135.9 \pm 12.6^{*}$ & $144.8 \pm 21.2$ & $143.8 \pm 21.5$ & $143.9 \pm 18.6$ \\
\hline $\begin{array}{l}\text { Left atrial } \\
\text { pressure } \\
\text { (mm Hg) }\end{array}$ & $5.1 \pm 1.9$ & $5.6 \pm 2.0$ & $5.1 \pm 2.3$ & $4.1 \pm 1.1$ & $5.7 \pm 0.5$ & $6.0 \pm 1.7$ & $5.5 \pm 1.5$ & $5.3 \pm 1.9$ & $4.7 \pm 1.4$ \\
\hline $\begin{array}{r}\text { Right atrial } \\
\text { pressure } \\
(\mathrm{mm} \mathrm{Hg})\end{array}$ & $4.2 \pm 1.7$ & $4.0 \pm 1.5$ & $4.0 \pm 1.4$ & $3.0 \pm 1.2$ & $4.0 \pm 1.9$ & $5.7 \pm 2.1^{*} \dagger$ & $5.1 \pm 1.6$ & $5.0 \pm 1.5$ & $4.7 \pm 1.3$ \\
\hline $\mathrm{pH}$ & $7.41 \pm 0.03$ & $7.42 \pm 0.03$ & $7.44 \pm 0.02^{*}$ & $+7.41 \pm 0.02$ & $7.39 \pm 0.05$ & $7.38 \pm 0.03$ & $7.36 \pm 0.03^{*}$ & $7.38 \pm 0.04$ & $7.37 \pm 0.03$ \\
\hline $\begin{array}{c}\mathrm{PaCO}_{2}(\mathrm{~mm} \\
\mathrm{Hg})\end{array}$ & $33.1 \pm 3.2$ & $32.7 \pm 2.1$ & $33.1 \pm 1.3$ & $38.4 \pm 2.4^{*} \dagger$ & $36.7 \pm 2.0^{*}$ & $37.7 \pm 3.7^{*}$ & $39.0 \pm 5.6^{*}$ & $37.7 \pm 4.7^{*}$ & $37.9 \pm 2.5^{*}$ \\
\hline $\begin{array}{c}\mathrm{PaO}_{2}(\mathrm{~mm} \\
\mathrm{Hg})\end{array}$ & $77.4 \pm 6.1$ & $86.4 \pm 6.4$ & $84.7 \pm 7.6$ & $73.7 \pm 5.7 \dagger$ & $83.6 \pm 17.9 \dagger$ & $61.6 \pm 7.0^{*} \dagger$ & $60.7 \pm 4.8$ & $59.6 \pm 4.7$ & $57.6 \pm 6.4^{*}$ \\
\hline
\end{tabular}

NO, Nitric oxide. Values are mean $\pm S D ; n=7$.

${ }^{*} P<.05$ versus before NO.

$\dagger P<.05$ versus previous column (analysis of variance).

monary arterial pressure and left pulmonary vascular resistance $(P<.05$; Table 1, Figure 1$)$. Right atrial pressure increased, and systemic arterial $\mathrm{Po}_{2}$ decreased $(P<.05)$. Left pulmonary blood flow, mean systemic arterial pressure, heart rate, left atrial pressures, systemic arterial $\mathrm{PCO}_{2}$, and $\mathrm{pH}$ remained unchanged from 24-hour NO values (Table 1). Ventilation alone, without inhaled NO, did not change mean pulmonary arterial pressure, pulmonary blood flow, pulmonary vascular resistance, left and right atrial pressures, heart rate, systemic arterial blood gases, or $\mathrm{pH}$. Mean systemic arterial pressure decreased slightly from $71.8 \pm 11.1 \mathrm{~mm}$ $\mathrm{Hg}$ to $61.0 \pm 7.4 \mathrm{~mm} \mathrm{Hg}(P<.05)$.

To determine the effects of inhaled NO on endogenous cGMP production, we determined plasma and lung tissue cGMP concentrations. We found that plasma cGMP concentrations increased on initiation of inhaled NO and remained increased during the 24-hour treatment period $(P<$ $.05)$. Withdrawal of NO was associated with a decrease in cGMP concentrations, which remained decreased 2 hours after discontinuation (Figure 2). Similarly, lung tissue concentrations of cGMP increased on initiation of inhaled NO
$(P<.05)$. However, this increase was not sustained during the 24-hour treatment period. Withdrawal of NO was also associated with a rapid decrease in tissue cGMP levels, which remained below baseline values during the 2-hour observation period $(P<.05$; Figure 3$)$.

Inhaled NO therapy decreased protein levels of both the $\alpha_{1}$ subunit of sGC and the $\beta_{1}$ subunit of sGC $(P<.05$; Figures 4 and 5). However, ventilation alone, without inhaled NO, did not change protein levels (Figures 4 and 5). PDE 5 protein levels were not changed during inhaled NO (Figure 6).

\section{Discussion}

Although many studies demonstrate a clear benefit in patient outcome with inhaled NO use, several safety concerns remain, including its potential acute and chronic adverse effects on endogenous endothelial function. ${ }^{1-4,9-12}$ For example, recent in vitro and in vivo data suggest that exogenous NO decreases endogenous NOS activity. ${ }^{13,14}$ However, the potential effects of inhaled NO on downstream mediators of the NO-cGMP cascade had not been investi- 


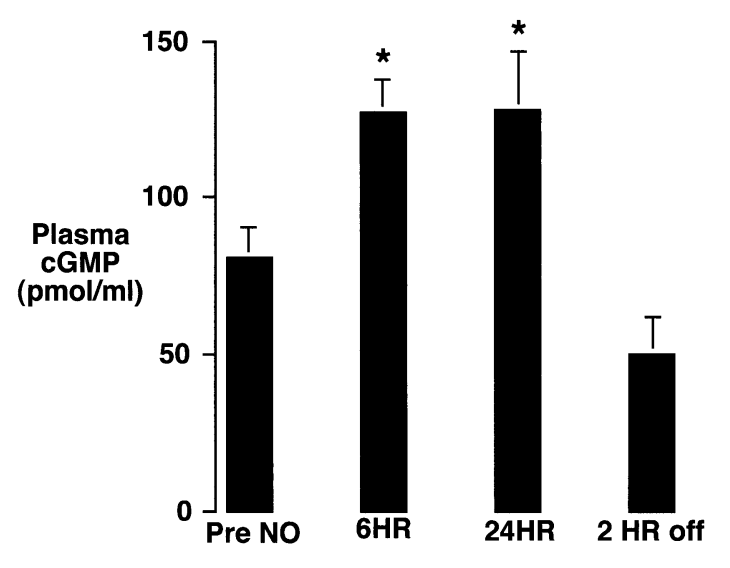

Figure 2. Changes in plasma cGMP concentrations before, during, and after 24 hours of inhaled NO (40 ppm) therapy; $n=6$. Values are mean \pm SEM. ${ }^{*} P<.05$ versus before NO (Pre NO).

gated. To our knowledge, this study is the first in vivo investigation of the effects of exogenous inhaled NO therapy on endogenous sGC and PDE 5 protein expression. Using a sequential lung biopsy technique in the intact 1-month-old lamb, we found that inhaled NO decreases lung tissue sGC protein levels by approximately 50\%, whereas PDE 5 levels are unchanged. These net alterations result in decreased endogenous pulmonary cGMP production during and after inhaled $\mathrm{NO}$ withdrawal.

Soluble GC is a heterodimeric enzyme composed of 2 subunits, termed $\alpha$ and $\beta$, that generates cGMP from guanosine $5^{\prime}$ triphosphate. ${ }^{19}$ Although much focus has been placed on potential alterations in NOS expression in pulmonary hypertensive disorders, data also suggest that potential changes in sGC expression and activity may be important in the pathophysiology of pulmonary hypertension. ${ }^{20-22}$ For example, decreased sGC protein levels and activity have been demonstrated in animal models of persistent pulmonary hypertension of the neonate. ${ }^{21,22}$ In vitro, this is associated with impairment in the pulmonary vasodilating response to NO donors and may play a role in the decreased responsiveness of some neonates with persistent pulmonary hypertension of the neonate. ${ }^{21,22}$ Decreases in sGC gene expression and activity have also been implicated in other vascular disorders, including essential hypertension. ${ }^{23}$ Although few data are available on the regulation of sGC, limited in vitro studies suggest that exogenous NO does alter sGC expression and activity. For example, in rat medullary interstitial cells, NO-donor compounds decreased the messenger RNA levels of both $\alpha_{1}$ and $\beta_{1}$ sGC subunits. ${ }^{16}$ In addition, in rat pulmonary artery smooth muscle cells, exposure to NO donors induced a cGMP-dependent decrease in sGC messenger RNA and protein levels. ${ }^{17}$ This study is the first in vivo demonstration that inhaled NO decreases pulmonary $\alpha_{1}$ and $\beta_{1}$ sGC protein levels. We
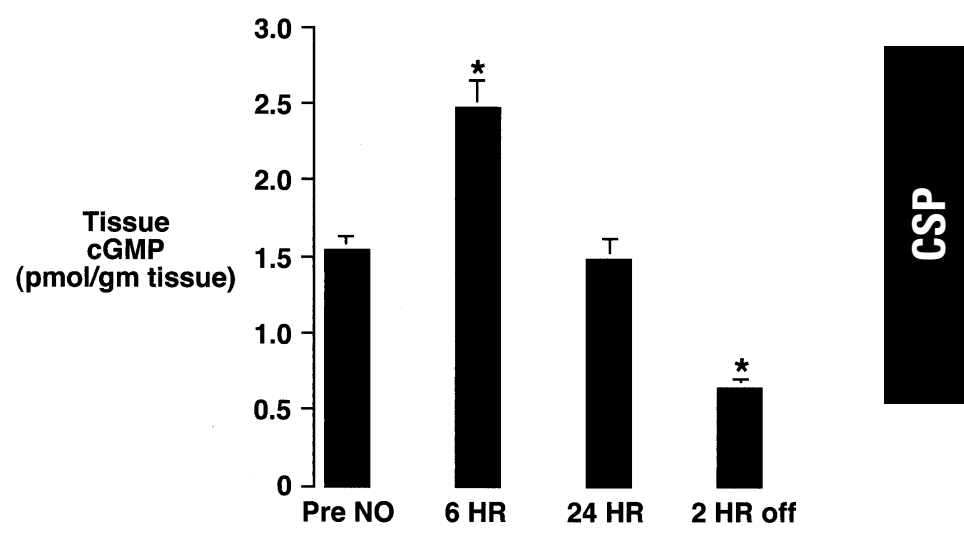

Figure 3. Changes in lung tissue cGMP concentrations before, during, and after 24 hours of inhaled NO (40 ppm) therapy; $\mathbf{n}=6$. Values are mean \pm SEM. ${ }^{*} P<.05$ versus before NO (Pre NO).

speculate that this effect is mediated by a direct effect of exogenous NO exposure, as demonstrated in pulmonary vascular smooth muscle cells. ${ }^{17}$ However, in the kidney, endogenous NOS inhibition has been demonstrated to decrease sGC activity. ${ }^{24}$ Therefore, a potential secondary effect of the decreased endogenous NOS activity, which occurs during NO exposure, on sGC cannot be excluded. ${ }^{13,14}$ These and other potential mechanisms require further study.

Intracellular cGMP concentrations are not determined simply by the accumulation of cGMP, but rather by a balance between synthesis and degradation. Cyclic nucleotide PDEs are the enzymes responsible for cGMP degradation. ${ }^{7}$ In the mammalian lung, there are a number of PDEs, but the cGMP-specific PDE, PDE 5, is prevalent, especially early in development. ${ }^{8}$ In this study we have demonstrated that the expression of PDE 5 is unchanged during inhaled NO therapy. As with sGC, little is known about the regulation of PDE 5 gene expression. However, developmental regulation and alterations in animal models of pulmonary hypertension have been demonstrated. ${ }^{8,25}$

Previous in vivo and in vitro data demonstrate that inhaled NO decreases endogenous NOS activity via an endothelin-1-dependent process, suggesting that decreased endogenous NOS activity mediates, at least in part, the rebound pulmonary hypertension associated with withdrawal of inhaled NO therapy. ${ }^{13,14,26,27}$ In this study, independent of changes in NOS, the net effect of decreased sGC without a compensatory decrease in PDE 5 may result in decreased cGMP production. This may explain why the initial increase in tissue cGMP concentrations during inhaled NO therapy did not persist throughout the entire 24-hour treatment period (Figure 3) and is a potential etiology for nonsustained NO responses demonstrated in human trials. ${ }^{9,10}$ Similarly, on withdrawal of exogenous NO, basal cGMP production will be decreased and may contrib- 
A

Inhaled NO

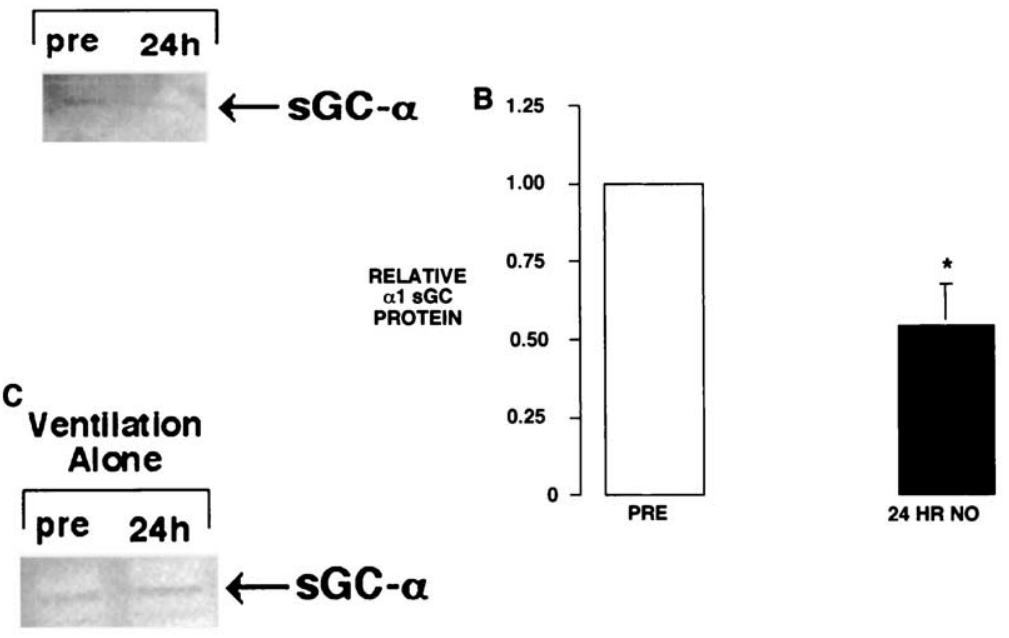

Figure 4. Western blot analysis for the $\alpha_{1}$ subunit of soluble guanylate cyclase protein in lung tissue before and after 24 hours of inhaled nitric oxide $(40 \mathrm{ppm})$ therapy. A, A representative Western blot is shown from protein extracts $(100 \mu \mathrm{g})$ prepared from lung tissue before and after NO therapy, separated on a $10 \%$ sodium dodecyl sulfate-polyacrylamide gel, electrophoretically transferred to Hybond membranes, and analyzed with a specific antiserum raised against the $\alpha_{1}$ subunit of soluble guanylate cyclase ( $\alpha_{1}$ sGC) protein. The sGC $\alpha_{1}$ protein expression was decreased during NO therapy. B, The densitometric values for relative $\alpha_{1}$ sGC protein (normalized to before NO [Pre] from 5 lambs. Values are mean \pm SEM. The $\alpha_{1}$ sGC protein expression was decreased during inhaled NO therapy. C, Representative Western blot of ventilation alone, without NO. The $\alpha_{1}$ sGC protein expression was unchanged during ventilation alone.

\section{A}

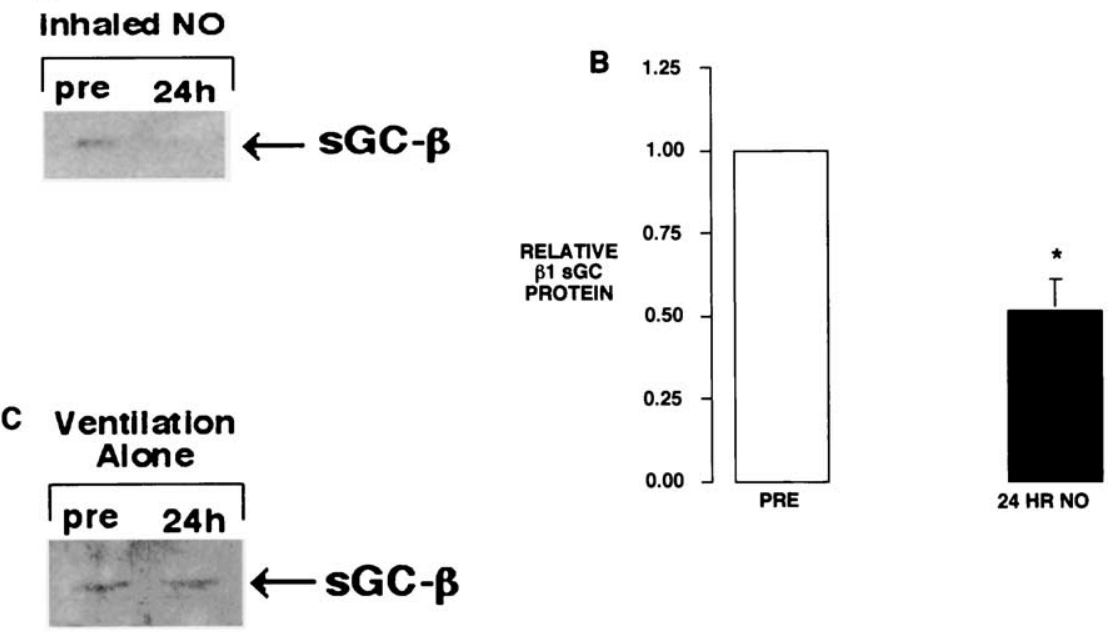

Figure 5. Western blot analysis for the $\beta_{1}$ subunit of soluble guanylate cyclase protein in lung tissue before and after 24 hours of inhaled nitric oxide $(40 \mathrm{ppm})$ therapy. A, A representative Western blot is shown from protein extracts $(100 \mu \mathrm{g})$ prepared from lung tissue before and after NO therapy, separated on a $10 \%$ sodium dodecyl sulfate-polyacrylamide gel, electrophoretically transferred to Hybond membranes, and analyzed with a specific antiserum raised against the $\beta_{1}$ subunit of soluble guanylate cyclase protein. The $\beta_{1}$ sGC protein expression was increased during inhaled NO therapy. B, The densitometric values for the $\beta_{1}$ subunit of soluble guanylate cyclase protein (normalized to before NO [Pre]) from 5 lambs. Values are mean \pm SEM. The $\beta_{1}$ sGC protein expression was increased during inhaled NO therapy. C, Representative Western blot of ventilation alone, without NO. The $\beta_{1}$ sGC protein expression was unchanged during ventilation alone. 
ute to the physiologic increase in pulmonary vascular resistance noted on NO withdrawal.

It is interesting to note that changes in plasma cGMP levels did not completely track with lung tissue cGMP levels (Figures 2 and 3). Similar to tissue levels, plasma levels increased on initiation of inhaled NO. However, unlike tissue levels, plasma cGMP levels remained increased throughout the 24-hour NO therapy and decreased only after NO was discontinued. Cyclic GMP production is the result of 2 major sources: activation of sGC via NO and activation of particulate guanylate cyclase via natriuretic peptides. ${ }^{28}$ Plasma cGMP levels reflect pulmonary and systemic vascular NO production, nonvascular NO production, and natriuretic peptide production, of which the myocardium is a major source. Lung tissue cGMP levels predominantly reflect vascular and nonvascular pulmonary NO production. Therefore, changes in tissue cGMP are more likely to reflect changes in endogenous pulmonary $\mathrm{NO}$ and subsequent cGMP production, whereas plasma levels are likely to be altered by other compensatory factors, such as changes in natriuretic peptide production. Although potential alterations in natriuretic peptide production and other nonpulmonary sources of cGMP during inhaled NO are unclear, the current data suggest potential changes that warrant further investigation.

Several limitations of this study are noteworthy. First, only 1 dose of inhaled NO (40 ppm) and 1 treatment duration (24 hours) were studied. In addition, rapid withdrawal of a high dose was used, as opposed to the slower weaning strategy that is often used clinically. Further investigations are needed to determine the potential effects of different doses, treatment durations, and weaning strategies on endogenous sGC and PDE 5. Finally, these studies were performed in lambs with normal pulmonary circulations. Patients with pulmonary hypertension, who are currently treated with inhaled $\mathrm{NO}$, often have preexisting aberrations in the NO-cGMP cascades. ${ }^{20}$ Further studies are warranted, and ongoing, to determine the effects of inhaled NO in abnormal pulmonary circulation.

This study is the first in vivo investigation of the effects of inhaled NO therapy on endogenous sGC and PDE 5 expression. We found that exogenous inhaled NO induces a significant decrease of sGC protein without a compensatory decrease in PDE 5. These changes were associated with a decrease in tissue cGMP concentrations during treatment. These data, taken together with previous investigations on NOS activity, suggest that decreased endogenous cGMP production mediates, at least in part, the nonsustained responsiveness to NO and the rebound pulmonary hypertension associated with withdrawal of inhaled NO therapy. Therefore, PDE 5 inhibitors may be useful co-therapies to augment the vasodilatory effects of inhaled $\mathrm{NO}$ and facilitate its discontinuation. In fact, sildenafil, a selective PDE 5
A
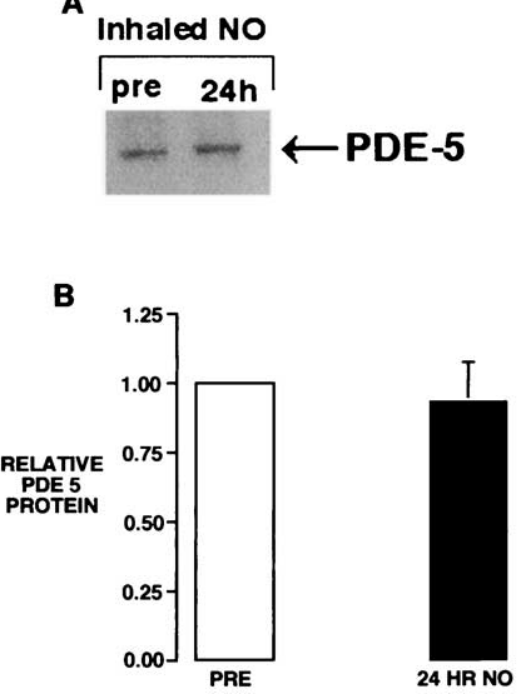

Figure 6. Western blot analysis for PDE 5 protein in lung tissue before and after 24 hours of inhaled nitric oxide $(40 \mathrm{ppm})$ therapy. A, A representative Western blot is shown from protein extracts $(100 \mu \mathrm{g})$ prepared from lung tissue before and after NO therapy, separated on a $10 \%$ sodium dodecyl sulfate-polyacrylamide gel, electrophoretically transferred to Hybond membranes, and analyzed with a specific antiserum raised against PDE 5. PDE 5 protein expression was unchanged during inhaled NO therapy. B, The densitometric values for relative PDE 5 protein (normalized to before NO [Pre] from 5 lambs. Values are mean \pm SEM. PDE 5 expression was unchanged during inhaled NO therapy.

inhibitor, has been shown in recent human studies to augment the effect of inhaled $\mathrm{NO}$ and facilitate its weaning. ${ }^{29,30}$ We speculate that a better understanding of the mechanism by which inhaled NO alters endogenous endothelial function will continue to lead to strategies that maximize the benefits of NO treatment while minimizing its toxicities, particularly during chronic therapy. In addition, these mechanisms may have important general clinical implications for a variety of both pulmonary and systemic vascular disorders, which include sickle cell disease, coronary artery disease, and nitrate tolerance.

\section{References}

1. Atz AM, Wessel DL. Inhaled nitric oxide in the neonate with cardiac disease. Semin Perinatol. 1997;21:441-55.

2. Canadian Inhaled Nitric Oxide Study Group and the NICHD Neonatal Research Network. The neonatal inhaled nitric oxide study in the term and near-term infant with hypoxic respiratory failure: a multicenter randomized trial. N Engl J Med. 1997;336:597-604.

3. Clark RH, Kueser TJ, Walker MW, Southgate WM, Huckaby JL, Perez JA, et al. Low-dose nitric oxide therapy for persistent pulmonary hypertension of the newborn. Clinical Inhaled Nitric Oxide Research Group. N Engl J Med. 2000;342:469-74.

4. Rossaint R, Falke KJ, Lopez F, Slama K, Pison U, Zapol WM. Inhaled nitric oxide for the adult respiratory distress syndrome. $N$ Engl J Med. 1993;328:399-405. 
5. Ignarro LJ, Ross G, Tillisch J. Pharmacology of endothelium-derived nitric oxide and nitrovasodilators. West J Med. 1991;154:51-62.

6. Christou H, Adatia I, Van Marter LJ, Kane JW, Thompson JE, Stark $\mathrm{AR}$, et al. Effect of inhaled nitric oxide on endothelin- 1 and cyclic guanosine 5'-monophosphate plasma concentrations in newborn infants with persistent pulmonary hypertension. J Pediatr. 1997;130: 603-11.

7. Beavo JA. Cyclic nucleotide phosphodiesterases: functional implications of multiple isoforms. Physiol Rev. 1995;75:725-48.

8. Sanchez LS, de la Monte SM, Filippov G, Jones RC, Zapol WM, Bloch KD. Cyclic-GMP-binding, cyclic-GMP-specific phosphodiesterase (PDE5) gene expression is regulated during rat pulmonary development. Pediatr Res. 1998;43:163-8.

9. Day RW, Allen EM, Witte MK. A randomized, controlled study of the 1-hour and 24-hour effects of inhaled nitric oxide therapy in children with acute hypoxemic respiratory failure. Chest. 1997;112:1324-31.

10. Dellinger RP, Zimmerman JL, Taylor RW, Straube RC, Hauser DL, Criner GJ, et al. Effects of inhaled nitric oxide in patients with acute respiratory distress syndrome: results of a randomized phase II trial. Inhaled Nitric Oxide in ARDS Study Group. Crit Care Med. 1998;26: $15-23$.

11. Atz A, Adatia I, Wessel D. Rebound pulmonary hypertension after inhalation of nitric oxide. Ann Thorac Surg. 1996;62:1759-64.

12. Lavoie A, Hall JB, Olson DM, Wylam ME. Life-threatening effects of discontinuing inhaled nitric oxide in severe respiratory failure. Am J Respir Crit Care Med. 1996;153:1985-7.

13. Black SM, Heidersbach RS, McMullan DM, Bekker JM, Johengen MJ, Fineman JR. Inhaled nitric oxide inhibits nitric oxide synthase activity in lambs. A potential mechanism for rebound pulmonary hypertension. Am J Physiol. 1999;277:H1849-56.

14. Sheehy AM, Burson MA, Black SM. Nitric oxide exposure inhibits endothelial NOS activity but not gene expression: a role for superoxide. Am J Physiol. 1998;274:L833-41.

15. Buga GM, Griscavage JM, Rogers NE, Ignarro LJ. Negative feedback regulation of endothelial cell function by nitric oxide. Circ Res. 1993;73:808-12.

16. Ujiiie K, Hogarth L, Danziger R, Drewett JG, Yuen P, Pang IH, et al. Homologous and heterologous desensitization of a guanylate cyclaselinked nitric oxide receptor in cultured rat medullary interstitial cells. J Pharmacol Exp Ther. 1994;270:761-7.

17. Filippov G, Bloch DB, Bloch KD. Nitric oxide decreases stability of mRNAs encoding soluble guanylate cyclase subunits in rat pulmonary artery smooth muscle cells. J Clin Invest. 1997;100:942-8.

18. Black SM, Sanchez LS, Bekker JM, Steinhorn RH, Fineman JR.
Increased expression of soluble guanylate cyclase and phosphodiesterase type 5 in lambs with increased pulmonary blood flow and pulmonary hypertension. Am J Physiol. 2001;281:L1051-7.

19. Kamisaki Y, Saheki S, Nakane M, Palmieri JA, Kuno T, Chang BY, et al. Soluble guanylate cyclase from rat lung exists as a heterodimer. J Biol Chem. 1986;261:7236-41.

20. Celermajer DS, Cullen S, Deanfield JE. Impairment of endotheliumdependent pulmonary artery relaxation in children with congenital heart disease and abnormal pulmonary hemodynamics. Circulation. 1993;87:440-6.

21. Steinhorn RH, Russell JA, Morin FC III. Disruption of cGMP production in pulmonary arteries isolated from fetal lambs with pulmonary hypertension. Am J Physiol. 1995;268:H1483-9.

22. Tzao C, Nickerson PA, Russell JA, Gugino SF, Steinhorn RH. Pulmonary hypertension alters soluble guanylate cyclase activity and expression in pulmonary arteries isolated from fetal lambs. Pediatr Pulmonol. 2001;31:97-105.

23. Ruetten H, Zabel U, Linz W, Schmidt H. Downregulation of soluble guanylate cyclase in young and aging spontaneously hypertensive rats. Circ Res. 1999;85:534-41.

24. Lewko B, Wendt U, Szczepanska-Konkel M, Stepinski J, Drewnowska $\mathrm{K}$, Angielski S. Inhibition of endogenous nitric oxide synthesis activates particulate guanylyl cyclase in the rat renal glomeruli. Kidney Int. 1997;52:654-9.

25. Sanchez LS, Bloch KD, Morin FC, Steinhorn RH. Phosphodiesterase 5 (PDE5) enzyme activity and gene expression are altered in newborn lambs with persistent pulmonary hypertension [abstract]. Pediatr Res. 1997;41:267A.

26. McMullan DM, Bekker JM, Johengen MJ, Hendricks-Munoz K, Gerrets R, Black SM, et al. Inhaled nitric oxide-induced rebound pulmonary hypertension: a role for endothelin-1. Am J Physiol. 2001;280: H777-85.

27. Wedgwood S, McMullan DM, Bekker JM, Fineman JR, Black SM. A role for ET-1 induced superoxide production in rebound pulmonary hypertension associated with inhaled NO therapy. Circ Res. 2001;89: 357-64.

28. Kone BC. Molecular biology of natriuretic peptides and nitric oxide synthases. Cardiovasc Res. 2001;51:429-41.

29. Atz AM, Lefler AK, Fairbrother DL, Uber WE, Bradley SM. Sildenafil augments the effect of inhaled nitric oxide for postoperative pulmonary hypertensive crises. J Thorac Cardiovasc Surg. 2002;124:628-9.

30. Atz AM, Wessel DL. Sildenafil ameliorates effects of inhaled nitric oxide withdrawal. Anesthesiology. 1999;91:307-10. 